\title{
Prevalence of HIV-associated esophageal candidiasis in sub-Saharan Africa: a systematic review and meta-analysis
}

\author{
Ronald Olum ${ }^{1}$, Joseph Baruch Baluku ${ }^{2,3}$, Ronald Okidi ${ }^{4}$, Irene Andia-Biraro ${ }^{5,6}$ and Felix Bongomin ${ }^{5,7^{*}}$ (D)
}

\begin{abstract}
Background: Esophageal candidiasis (OC) is a common AIDS-defining opportunistic infection. Antiretroviral therapy (ART) reduces the occurrence of $O C$ and other opportunistic infections among persons living with HIV (PLHIV). We sought to determine and compare the prevalence of OC in the ART and pre-ART era among PLHIV in sub-Saharan Africa (SSA).
\end{abstract}

Methods: We searched PubMed, Embase, Web of Science, and the African Journals Online databases to select studies in English and French reporting the prevalence of HIV-associated OC in SSA from January 1980 to June 2020. Reviews, single-case reports, and case series reporting $<10$ patients were excluded. A random-effect cumulative meta-analysis was performed using STATA 16.0, and trend analysis performed using GraphPad Prism 8.0.

Results: Thirteen eligible studies from 9 SSA countries including a total of 113,272 patients were qualitatively synthesized, and 9 studies were included in the meta-analysis. Overall pooled prevalence of HIV-associated OC was 12\% (95\% confidence interval (Cl): 8 to $\left.15 \%, l^{2}=98.61 \%, p<.001\right)$. The prevalence was higher in the pre-ART era compared to the ART era, but not to statistical significance (34.1\% vs. $8.7 \%, p=0.095)$. In those diagnosed by endoscopy, the prevalence was higher compared to patients diagnosed by non-endoscopic approaches, but not to statistical significance $(35.1 \%$ vs. $8.4 \%, p=.071)$. The prevalence of OC significantly decreased over the study period (24 to $16 \%, p<.025)$.

Conclusion: The prevalence of OC among PLHIV in the ART era in SSA is decreasing. However, OC remains a common problem. Active endoscopic surveillance of symptomatic patients and further empirical studies into the microbiology, optimal antifungal treatment, and impact of OC on quality of life of PLHIV in SSA are recommended.

Keywords: Esophageal candidiasis, Prevalence, HIV/AIDS, Sub-Saharan Africa, Review, Meta-analysis

\section{Introduction}

Sub-Saharan Africa (SSA) remains the region most affected by the human immune deficiency virus (HIV)/acquired immune deficiency syndrome (AIDS) pandemic [1]. Of the estimated nearly 38 million people living with HIV (PLHIV) globally at the end of 2018, over 60\% (

\footnotetext{
* Correspondence: drbongomin@gmail.com

${ }^{5}$ Department of Medicine, School of Medicine, College of Health Sciences,

Makerere University, Kampala, Uganda

7Department of Medical Microbiology and Immunology, Faculty of Medicine,

Gulu University, Gulu, Uganda

Full list of author information is available at the end of the article
}

25.7 million) are found in SSA alone [1, 2]. In 2018, a total of 800,000 new infections and 310,0000 deaths were reported from eastern and southern Africa alone, accounting for $47 \%$ and $40 \%$ of the global AIDS-related deaths [2].

Mucocutaneous manifestations due to opportunistic infections and malignancies are the most common and usually the first recognizable clinical presentation in patients with HIV/AIDS [3, 4]. Persistent oropharyngeal candidiasis and Esophageal candidiasis (OC) or candidiasis of the trachea, bronchi, or lungs are common AIDSdefining lesions seen in PLHIV in World Health

(c) The Author(s). 2020 Open Access This article is licensed under a Creative Commons Attribution 4.0 International License, which permits use, sharing, adaptation, distribution and reproduction in any medium or format, as long as you give

appropriate credit to the original author(s) and the source, provide a link to the Creative Commons licence, and indicate if changes were made. The images or other third party material in this article are included in the article's Creative Commons licence, unless indicated otherwise in a credit line to the material. If material is not included in the article's Creative Commons licence and your intended use is not permitted by statutory regulation or exceeds the permitted use, you will need to obtain permission directly from the copyright holder. To view a copy of this licence, visit http://creativecommons.org/licenses/by/4.0/. 
Organization (WHO) clinical stages III and IV or CD4 T lymphocyte cell count $<200$ cells $/ \mathrm{mm}^{3}$ [5]. OC typically occurs at relatively lower CD4 cell counts than oropharyngeal candidiasis [6]. High HIV viral loads have also been associated with $\mathrm{OC}$ independent of CD4 counts [7].

$\mathrm{OC}$ is the most common cause of infectious esophagitis in patients with advanced HIV disease, mainly caused by the yeast Candida albicans but also other non-albicans Candida species such as C. glabrata, $C$. tropicalis, and C. dubliniensis [8]. OC is associated with substantial morbidity and adversely affects the quality of life of the affected persons owing to the dysphagia, odynophagia, retrosternal chest pain, and extreme weight loss attributed to the disease [9]. On endoscopic examination, white mucosal plaque-like lesions, erythema, and exudates adherent to the mucosa are frequently observed [9]. Biopsy or mucosal brushing samples reveals pseudohyphae of the Candida species and is the preferred method of diagnosis of OC [9]. Microbiological confirmation, speciation, and antifungal susceptibility are achieved through a culture of the endoscopically acquired samples.

Between 10 and 15\% of PLHIV will develop esophageal candidiasis at one point in their life-time [10]. OC is observed in over $20 \%$ of PLHIV with CD4 counts of 200 cells or less who are currently not on antiretroviral therapy (ART) [11]. Early in the HIV/AIDS epidemic in SSA, OC frequently with oropharyngeal candidiasis was observed in over $80 \%$ of hospitalized PLHIV [12]. However, with the global rollout of ART and the recent "test-andtreat strategy," the prevalence of OC has greatly reduced due to early ART initiation [13].

We hypothesized that with over 10 years of the widespread use of ART and enhanced anti-infective prophylaxis in SSA, the occurrence of opportunistic diseases including $\mathrm{OC}$ is expected to have significantly reduced. However, there is a scarcity of studies to demonstrate the trend of OC in the pre-ART and ART era in SSA. Such information is not only valuable for epidemiological purposes but also help guide targeted clinical care of this vulnerable population. The aim of this study, therefore, was to determine the prevalence and the trend in the prevalence of OC among PLHIV in SSA over the past nearly 40 years of the HIV/AIDS pandemic.

\section{Methods}

\section{Study design}

This systematic review and meta-analysis were conducted according to the criteria outlined in the Preferred Reporting Items for Systematic Reviews and MetaAnalyses (PRISMA) statement [14]. The PRISMA checklist is available as a Supplementary File. We did not register the study protocol prior to commencement of the research.

\section{Search strategy}

With the help of a qualified medical librarian, all studies published from January 1980 to June 2020 were searched from EMBASE, PubMed, Web of Science, and the African Journals Online (AJOL).

The following search terms were used: "oesophageal candidiasis" OR "esophageal candidiasis" OR "candidal oesophagitis" OR "candidal esophagitis" OR "Candida infection of the oesophagus" OR "monilial oesophagitis" AND "human immune deficiency virus" OR "HIV" OR "acquired immune deficiency syndrome" OR "AIDS" AND "Africa South of Sahara" OR "sub-Saharan Africa" OR "Angola" OR "Benin" OR "Botswana" OR "Burkina Faso" OR "Burundi" OR "Cameroon" OR "Cape Verde" OR "Central African Republic" OR "Chad" OR "Comoros" OR "Democratic Republic of Congo" OR "Cote d'Ivoire" OR "Eritrea" OR "Eswatini" OR "Ethiopia" OR "Gabon" OR "Gambia" OR "Ghana" OR "Guinea" OR "Guinea-Bissau" OR "Kenya" OR "Lesotho" OR "Liberia" OR "Madagascar" OR "Malawi" OR "Mali" OR "Mauritania" OR "Mauritius" OR "Mozambique" OR "Namibia" OR "Niger" OR "Nigeria" OR "Rwanda" OR "Sao Tome and Principe" OR "Senegal" OR "Seychelles" OR "Sierra Leone" OR "Somalia" OR "South Africa" OR "South Sudan" OR "Sudan" OR "Tanzania" OR "Togo" OR "Uganda" OR "Zaire" OR "Zambia" OR "Zimbabwe".

Besides, we performed a manual literature search for all the references of the included articles to find applicable studies. The search was limited to human studies only. Studies written in English and French, which are the most common languages, published in sub-Saharan Africa were selected.

\section{Study selection criteria}

Duplicate studies were identified and merged using the HDAS program. Titles and abstracts were primarily screened by two independent reviewers (F.B and R.O) to exclude those not related to this study. After the initial screening, full texts of potentially eligible studies were retrieved and examined for eligibility.

Studies that met the following inclusion criteria were included:

i. Retrospective or prospective observational studies from January 1980 to June 2020.

ii. Published in the English and French languages.

iii. Reporting prevalence of HIV-associated OC in countries located in SSA.

Studies reporting oropharyngeal candidiasis or did not specify the location of upper gastrointestinal candidiasis 
were excluded. Single-case reports and case series reporting less than 10 cases were also excluded from the study.

\section{Data extraction}

A pre-designed macros form in Microsoft Excel 2016 was used to extract data from each article. The following items were extracted:

- Study characteristics; authors, year of publication, study country, study design.

- Study characteristics; age (mean or median), sex, the sample size of the participants, number of patients diagnosed with OC (prevalence), how the diagnosis was made (non-endoscopic vs. endoscopy), and the period of data collection in each study.

Two independent reviewers ( $\mathrm{RO}$ and $\mathrm{FB}$ ) extracted data, and any differences were resolved by discussion and consensus. The corresponding authors for eligible studies with missing data were contacted by email for clarification.

\section{Operational definition}

The pre-ART era was defined as patients diagnosed with HIV-associated OC before 2004 (1981-2003) and ART era between 2004 and to date. ART era was further subdivided into early ART era (2004-2014) when ART was limited to only severely ill patients (WHO clinical stages III and IV or CD4 count of 200 cells/ $\mu$ l or less) [15] and late ART era (2014 to date) when ART is more available with the adoption of "test and treat" strategy for all patients diagnosed with HIV [16].

\section{Qualitative assessment}

All the eligible studies included were assessed for risk of bias using the Critical Appraisal Skills Programme (CASP) checklist. The risk of bias in individual studies was graded as low, moderate, and high. Studies with a high risk of bias were excluded from the meta-analysis.

\section{Study outcomes}

The study outcome is the pooled prevalence and the trend in the prevalence of $\mathrm{OC}$ in patients with HIV/ AIDS living in SSA.

\section{Analysis}

All analyses were performed using Microsoft Office 2016 (Microsoft Inc., Washington, USA), GraphPad Prism 8.0, and STATA 16.0 statistical software (Stata Corp, College Station, Texas, USA). A random effect cumulative metaanalysis was performed using in STATA 16.0 to illustrate the trends in the prevalence of HIV-associated OC and presented in a forest plot. Heterogeneity across studies was assessed using $\mathrm{Q}$ statistics and $I^{2}$ value. A funnel plot was generated to assess for publication and sensitivity analysis performed. Mann-Whitney test was performed in GraphPad Prism 8.0. $p<0.05$ was considered statistically significant at the $95 \%$ confidence interval (CI). Descriptive statistics were used to summarize data from individual studies. A narrative synthesis was also employed to present the results and discussion of the different studies included.

\section{Results}

\section{Study characteristics}

Table 1 summarizes the characteristics of all the studies included in the systematic review. Thirteen studies from 9 SSA countries (Tanzania, $n=1$; Togo, $n=2$; Cameroon, $n=1$; Malawi, $n=2$; Mozambique, $n=1$; Zambia, $n=1$; Nigeria, $n=1$; Kenya, $n=1$; and Uganda, $n=3$;) were eligible from the studies identified through database and manual literature search (Fig. 1). Only 9 studies [10, 17-24] reporting OC in general HIV populations were included in the quantitative synthesis and 4 studies [25-28] in specific HIV populations were excluded from the meta-analyses. Overall, 9,150 patients were diagnosed with $\mathrm{OC}$ of the 113,272 HIV patients in SSA who were assessed between 1989 and 2014. The majority of the studies $(n=7)$ were retrospective studies, and one was a randomized clinical trial. Five of the studies were conducted before the introduction of ART.

\section{Prevalence of esophageal candidiasis}

Four of the 13 studies recruited a more restricted group of patients [25-28], with the prevalence of OC ranging between $28 \%$ and $55 \%$. These studies were excluded from the meta-analysis. Of the 9 studies included in the meta-analysis, the pooled prevalence of HIV-associated OC in SSA was $12 \%$ (95\% CI. 8 to $15 \%, I^{2}=98.61 \%, P<$ $0.001)$, Fig. 2. The prevalence ranged from 1 to $52 \%$ across individual studies. Only two studies $[17,18]$ were within the funnel plot, Fig. 3. No study described the microbiological etiology of the Candida species responsible.

\section{Trends in HIV-associated esophageal candidiasis}

Overall, the prevalence of OC significantly decreased over the over three decades of the HIV pandemic in SSA, Figs. 4 and 5. Cumulative prevalence ranged from $24 \%$ in 1999 to $16 \%$ in 2018 , Fig. 5 . OC was frequently reported with oral candidiasis in some studies $[10,23]$.

\section{Diagnosis of esophageal candidiasis}

In 7 studies, diagnosis of OC was solely made through upper gastrointestinal endoscopy, non-endoscopic (clinical or histology) in 5 studies, and not specified in one study (Table 1). Overall, the mean prevalence of OC in 
Table 1 Characteristics of included studies

\begin{tabular}{|c|c|c|c|c|c|c|c|c|c|}
\hline Study & Country & Study type & Study population & $\begin{array}{l}\text { Age: median } \\
\text { or mean (IQR) } \\
\text { years }\end{array}$ & $\operatorname{Sex}(M / F)$ & $\begin{array}{l}\text { Patients } \\
(N)\end{array}$ & Cases & Diagnosis & $\begin{array}{l}\text { ART } \\
\text { period }\end{array}$ \\
\hline Mushi et al. [25]* & Tanzania & $\begin{array}{l}\text { Retrospective } \\
\text { observational }\end{array}$ & $\begin{array}{l}\text { Patients attending the endoscopy } \\
\text { unit between August 19,2009, } \\
\text { and September 19, } 2014\end{array}$ & - & $-/-$ & 15 & 8 & Endoscopic & ART Era \\
\hline $\begin{array}{l}\text { Lawson-Ananissoh } \\
\text { et al. [17] }\end{array}$ & Togo & $\begin{array}{l}\text { Retrospective } \\
\text { observational }\end{array}$ & $\begin{array}{l}\text { Lome' University Hospital } \\
\text { Hepato-Gastroenterology } \\
\text { Department records covering } \\
\text { a 10-year period; } 2005 \text { to } 2014\end{array}$ & 41 & $201 / 231$ & 432 & 32 & Not specified & ART Era \\
\hline Andoulo et al. [27]* & Cameroon & $\begin{array}{l}\text { Prospective } \\
\text { observational }\end{array}$ & $\begin{array}{l}\text { Adult patients referred for upper } \\
\text { gastrointestinal endoscopy from } \\
2014 \text { to } 2015 \text { to university teaching } \\
\text { hospitals at Yaounde and Douala. }\end{array}$ & 43.8 (20 to 71$)$ & $27 / 29$ & 56 & 34 & Endoscopic & ART Era \\
\hline Rubaihayo et al. [18] & Uganda & $\begin{array}{l}\text { Retrospective } \\
\text { observational }\end{array}$ & $\begin{array}{l}\text { Patients attending TASO HIV Clinic } \\
\text { in } 4 \text { TASO centers in Uganda from } \\
2002 \text { to } 2009\end{array}$ & 33 (27 to 40$)$ & $\begin{array}{l}39379 / \\
69240\end{array}$ & 108619 & 8778 & $\begin{array}{l}\text { Non- } \\
\text { endoscopic }\end{array}$ & ART Era \\
\hline $\begin{array}{l}\text { Brentlinger et al. } \\
\text { [20] }\end{array}$ & Mozambique & $\begin{array}{l}\text { Prospective } \\
\text { observational }\end{array}$ & $\begin{array}{l}\text { HIV-infected ambulatory patients } \\
18 \text { years of age and above } \\
\text { presenting for scheduled (routine) } \\
\text { or unscheduled care at three } \\
\text { participating health centers, } \\
\text { with current } \mathrm{Hb}<10 \mathrm{~g} / \mathrm{dl} \text { in } 2012\end{array}$ & 29 (23 to 36$)$ & $62 / 262$ & 324 & 4 & $\begin{array}{l}\text { Non- } \\
\text { endoscopic }\end{array}$ & ART Era \\
\hline Bagny et al. [19] & Togo & $\begin{array}{l}\text { Prospective } \\
\text { observational }\end{array}$ & $\begin{array}{l}\text { All adult HIV patients admitted to } \\
\text { hepato-gastroenterology } \\
\text { department of the Centre } \\
\text { Hospitalier Universitaire Lome' } \\
\text { campus fom January } 1 \text { to } \\
\text { December 31, } 2011\end{array}$ & 38.8 (20 to 65$)$ & $15 / 67$ & 82 & 24 & Endoscopic & ART Era \\
\hline Preidis et al. [21] & Malawi & $\begin{array}{l}\text { Retrospective } \\
\text { observational }\end{array}$ & $\begin{array}{l}\text { Data from all HIV patient } \\
\text { September 1, 2007, and } \\
\text { December 31, } 2008\end{array}$ & $\begin{array}{l}21.8(11.1 \text { to } \\
44.6)\end{array}$ & $479 / 405$ & 884 & 35 & $\begin{array}{l}\text { Non- } \\
\text { endoscopic }\end{array}$ & ART Era \\
\hline Zachariah et al. [22] & Malawi & $\begin{array}{l}\text { Retrospective } \\
\text { cohort }\end{array}$ & $\begin{array}{l}\text { HIV patients receiving care in } \\
\text { Thylo District health centers } \\
\text { from } 2006 \text { to } 2008\end{array}$ & 35 & $706 / 1610$ & 2289 & 53 & $\begin{array}{l}\text { Non- } \\
\text { endoscopic }\end{array}$ & ART Era \\
\hline Okeke et al. [26]* & Nigeria & $\begin{array}{l}\text { Retrospective } \\
\text { observational }\end{array}$ & $\begin{array}{l}\text { Patients who underwent } \\
\text { endoscopy at Jos University } \\
\text { Teaching Hospital }\end{array}$ & - & $-1-$ & 52 & 18 & Endoscopic & $\begin{array}{l}\text { Pre- } \\
\text { ART }\end{array}$ \\
\hline Mohamed et al. [10] & Kenya & $\begin{array}{l}\text { Prospective } \\
\text { observational }\end{array}$ & $\begin{array}{l}\text { Consecutive patients } 12 \text { years } \\
\text { and above referred between } \\
2000 \text { and } 2001\end{array}$ & 32 (18 to 55$)$ & $20 / 32$ & 52 & 27 & Endoscopic & $\begin{array}{l}\text { Pre- } \\
\text { ART }\end{array}$ \\
\hline Morgan et al. [24] & Uganda & $\begin{array}{l}\text { Prospective } \\
\text { observational }\end{array}$ & $\begin{array}{l}\text { Prevalent and incident } \\
\text { community cases from } \\
1989 \text { to } 1998\end{array}$ & $\begin{array}{l}\text { Males: } 36.9 \\
\text { Females: } 36.5\end{array}$ & $38 / 34$ & 72 & 19 & $\begin{array}{l}\text { Non- } \\
\text { endoscopic }\end{array}$ & $\begin{array}{l}\text { Pre- } \\
\text { ART }\end{array}$ \\
\hline Ravera et al. [23] & Uganda & $\begin{array}{l}\text { Randomized } \\
\text { clinical trial }\end{array}$ & $\begin{array}{l}\text { From September } 1994 \text { to } \\
\text { December 1995, } 320 \text { consecutive } \\
\text { AIDS patients were observed at } \\
\text { the Gastroenterology Department } \\
\text { of Hoima Hospital in Uganda }\end{array}$ & 23.7 & $27 / 50$ & 320 & 77 & Endoscopic & $\begin{array}{l}\text { Pre- } \\
\text { ART }\end{array}$ \\
\hline Kelly et al. [28]* & Zambia & $\begin{array}{l}\text { Cross- } \\
\text { sectional }\end{array}$ & $\begin{array}{l}\text { HIV seropositive patients } \\
\text { presenting with persistent } \\
\text { diarrhea at the University } \\
\text { Teaching Hospital, Lusaka }\end{array}$ & $\begin{array}{l}\text { Male: } 30 \\
\text { Female: } 29.5 \\
\text { Range: } 16-64\end{array}$ & $40 / 35$ & 75 & 41 & Endoscopic & $\begin{array}{l}\text { Pre- } \\
\text { ART }\end{array}$ \\
\hline
\end{tabular}

Abbreviations: AIDS acquired immunodeficiency syndrome, $A R T$ anti-retroviral therapy, TASO The AIDS Support Organization, $I Q R$ interquartile range, $M$ male, $F$ female, HIV human immunodeficiency virus

*Not included in the meta-analysis as the selection of the patient was from a restricted population with a higher likelihood of over estimation of the prevalence of OC

the 9 studies included in quantitative synthesis was higher in endoscopic diagnosis (35.1\%) than in nonendoscopic diagnoses $(8.4 \%)$, but this was not statistically significant $(p=0.071)$, Fig. 6 .

\section{Antiretroviral therapy and esophageal candidiasis}

Five studies were conducted during the pre-ART era and 8 studies during the ART era (Table 1). The mean prevalence of $\mathrm{OC}$ in the 9 studies included in quantitative synthesis was higher in studies conducted during the pre-ART era (34.1\%) compared to the ART era $(8.7 \%)$. However, this difference was not statistically significant ( $p=0.095$, Fig. 6). In sub-analysis, the mean prevalence of HIV-associated OC was higher in endoscopically diagnosed patients than in non-endoscopic diagnosed PLHIV during both pre-ART and ART era (17.8\% vs. $4.6 \%)$. However, this difference was not statistically significant $(p=0.071)$, Fig. 7 . 


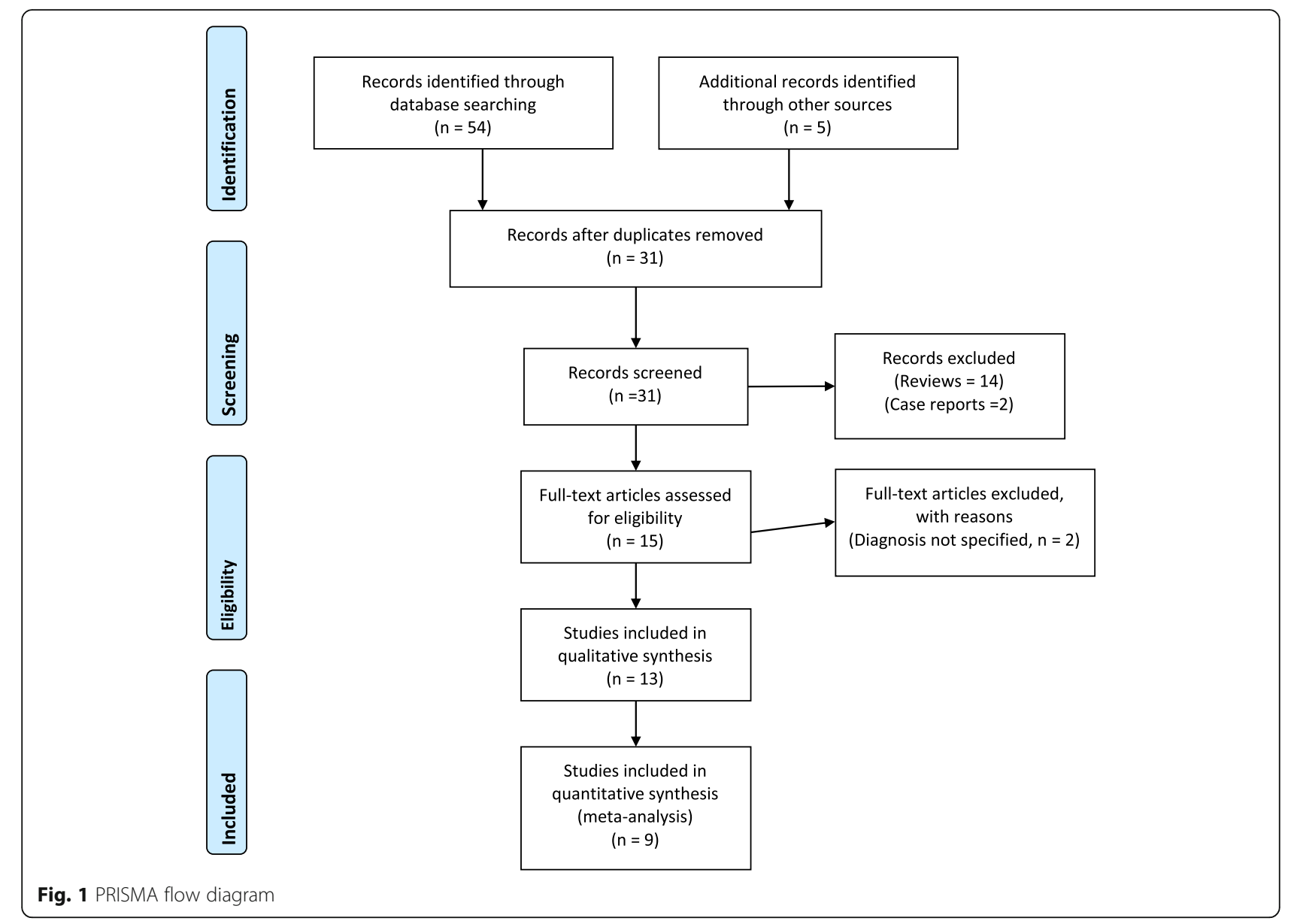

\section{Discussion}

This systematic review aimed to determine the prevalence and the trend in the prevalence of $\mathrm{OC}$ in the preART and ART era. Overall, in this large review, the pooled prevalence of OC was $12 \%$ (95\% CI, 8 to $15 \%)$, which is comparable to the global data on the lifetime prevalence (10 to $15 \%$ ) of OC among patients with HIV/ AIDS [6]. A significant decline in the prevalence of OC was observed between 1996 and 2015 from as high as over $65 \%$ to as low as $<10 \%$. This decline reflects the introduction and the widespread use of ART across SSA, mainly supported by the President's Emergency Plan for AIDS Relief (PEPFAR) initiative launched in 2004. Consistent use of ART improves immunological response and leads to viral suppression in PLHIV with a subsequent decline in the frequencies of opportunistic infections, including OC [29-31]. The small increase in the prevalence of OC observed between 2012 and 2014 could be due to the increasing number of the "late presenters" $[32,33]$. That is, patients presenting to care with advanced HIV disease or those already on ART representing to care with advanced HIV disease due to treatment failure $[34,35]$. The prevalence of $\mathrm{OC}$ was higher in those diagnosed endoscopically compared to those diagnosed clinically irrespective of the ART era. This could be due to the low sensitivity of clinical diagnosis for the definitive diagnosis of OC.

In a large study evaluating over 100,000 PLHIV in Uganda, the prevalence of OC was stratified into preART period (male 9.8\%, female 7.2\%), early ART (male $10 \%$, female $7.2 \%$ ) and late ART (male 2.9\%, female 2.6\%) [18]. However, the method of diagnosis of OC was not indicated in this study, but most likely clinical since a majority of these patients were managed as outpatients and esophagogastroduodenoscopy (OGD) is not widely available across the country.

In Malawi, OC significantly correlated with inpatient mortality $(p<.05)$ with up to $8.8 \%$ of deaths reported [21]. In this study, the mean CD4 count of the patients who died with OC was 194.1 cells $/ \mathrm{mm}^{3}$, and only $23.1 \%$ of the patients in the study were on ART. Mohamed and colleagues found that more esophageal lesions were significantly associated with CD4 counts less than 200 cells $/ \mathrm{mm}^{3}$ [10]. Before the widespread use of ART, the median CD4 count for patients with OC was 101 (29 to 280) cells $/ \mathrm{mm}^{3}$ in a Ugandan prospective study and the median survival time was 3.1 months in the untreated AIDS patients [24]. 


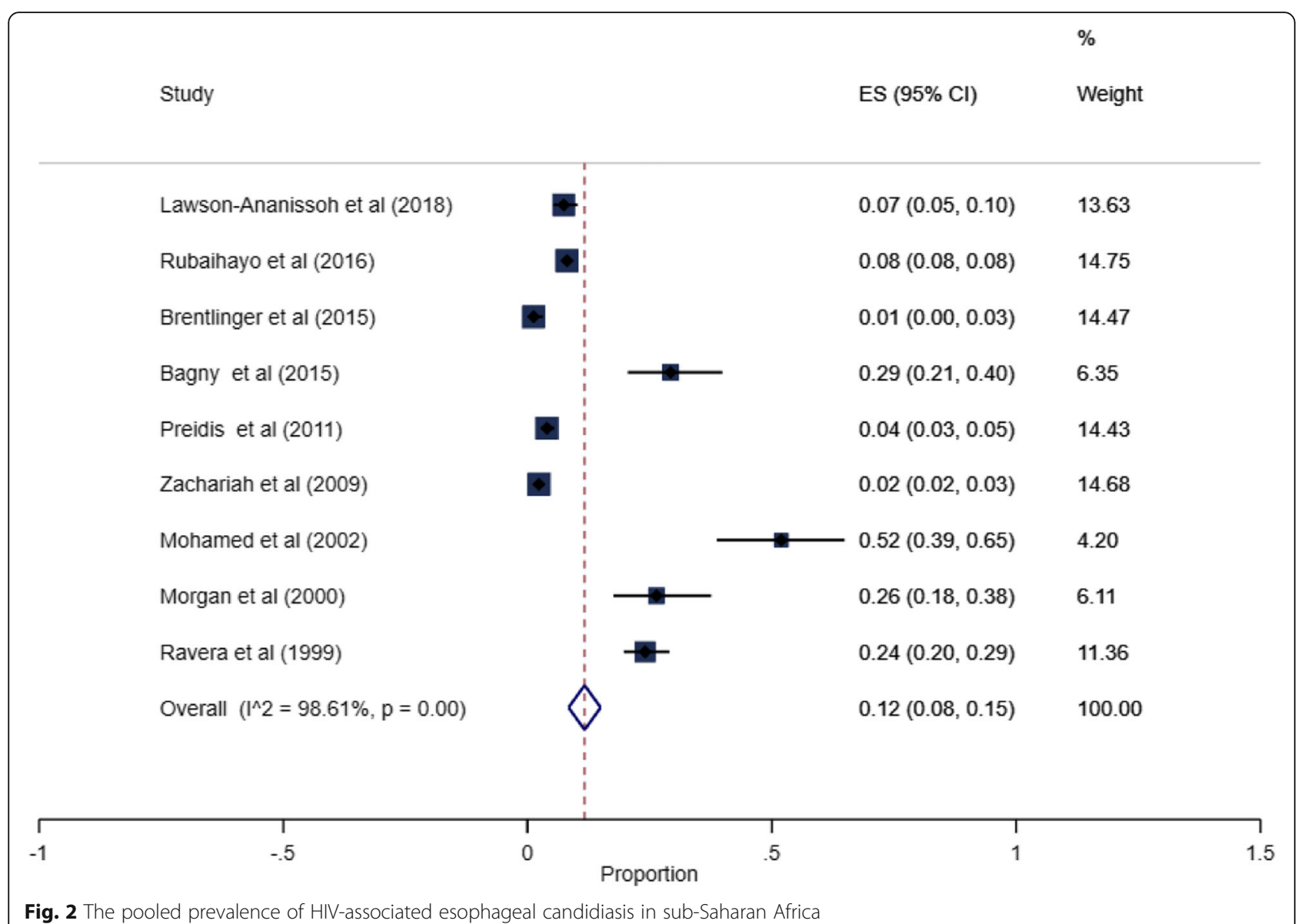

Fig. 2 The pooled prevalence of HIV-associated esophageal candidiasis in sub-Saharan Africa

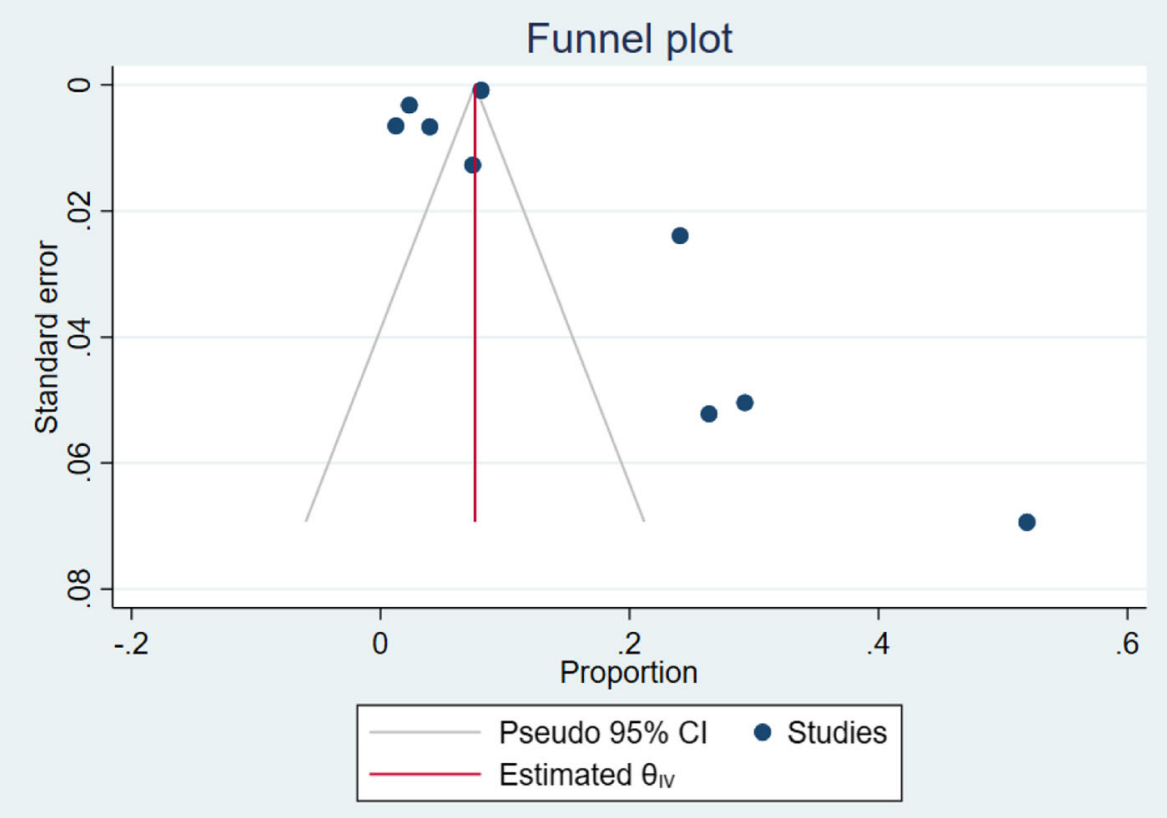

Fig. 3 A funnel plot showing the distribution of eligible studies 


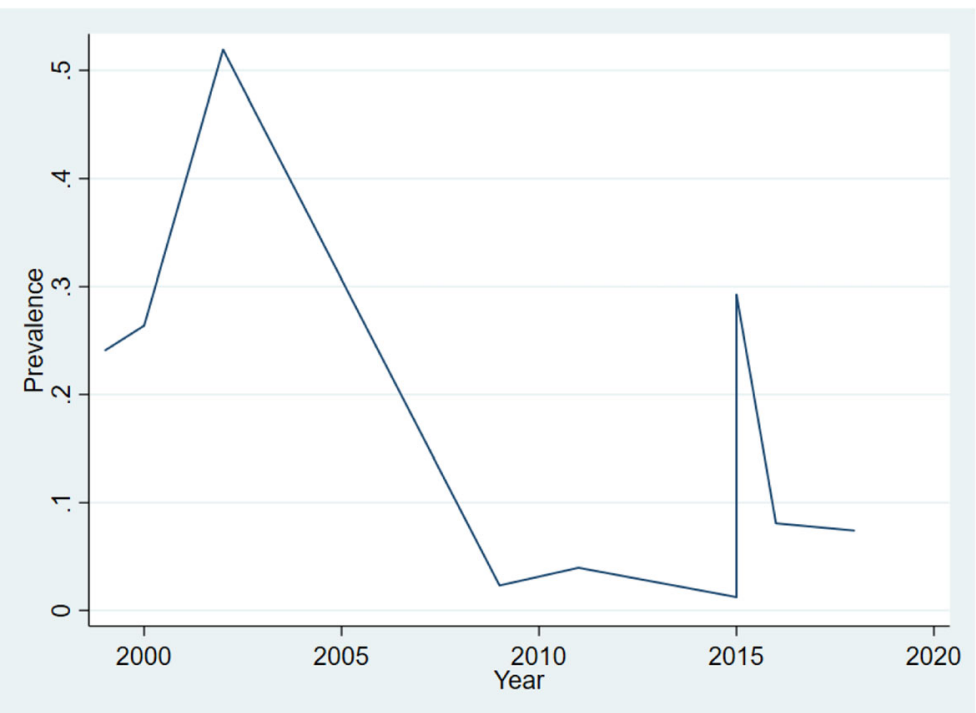

Fig. 4 Trends in the prevalence of HIV-associated esophageal candidiasis in sub-Saharan Africa

The diagnosis of OC remains a challenge in SSA. It is thus not surprising that in at least 4 of the studies we have evaluated, the diagnosis was made on a clinical basis $[18,20-22,24]$. OGD is not widely available, expensive for the patients and the expertise to perform the procedure is limited.

However, in most instances, suspected cases of OC are empirically treated with systemic antifungals. The resolution of classical symptoms of the disease (odynophagia and dysphagia) over several days of antifungal therapy is considered an alternative diagnostic approach [36]. Fluconazole and itraconazole are firstline agents that are equally efficacious. Alternative agents such as amphotericin B and the echinocandins are used in patients who have contraindications to, develop resistance, or are clinically failing while on systemic triazoles [36].
Lack of response to systemic antifungal response is uncommon and usually due to antifungal resistance or a wrong clinical diagnosis [36]. C. albicans, the most common cause of OC is usually susceptible to commonly prescribed triazole antifungals (fluconazole) [36]. However, in patients with previous exposure to the triazoles or those infected with non-albicans Candida species, treatment failure is common. C. krusei is intrinsically resistant to fluconazole but C. dubliniensis and C. glabrata which are more common in HIV have high minimum inhibitory concentrations to this commonly used antifungal [36]. Therefore, microbiological confirmation of the etiology and anti-fungal susceptibility testing is recommended for this group of patients [36]. In those clinically diagnosed, OGD should be performed to rule out infectious and malignant differential diagnoses such as herpes simplex virus (HSV), cytomegalovirus, and

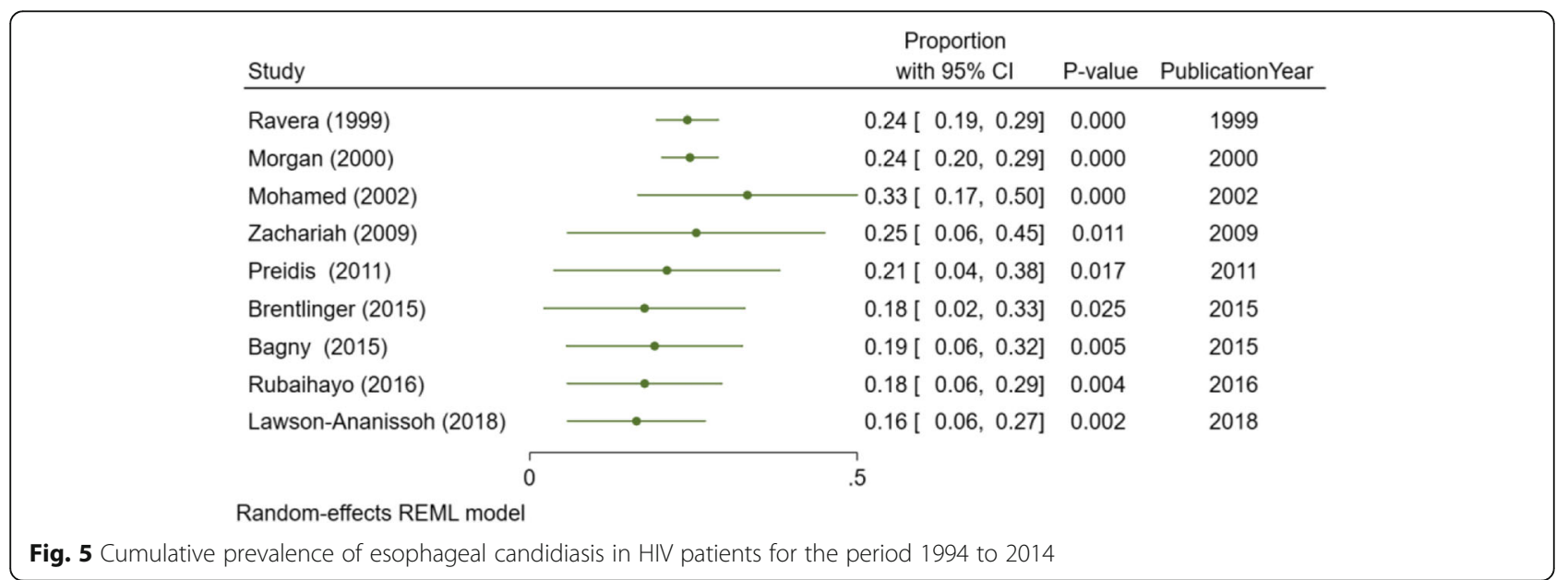



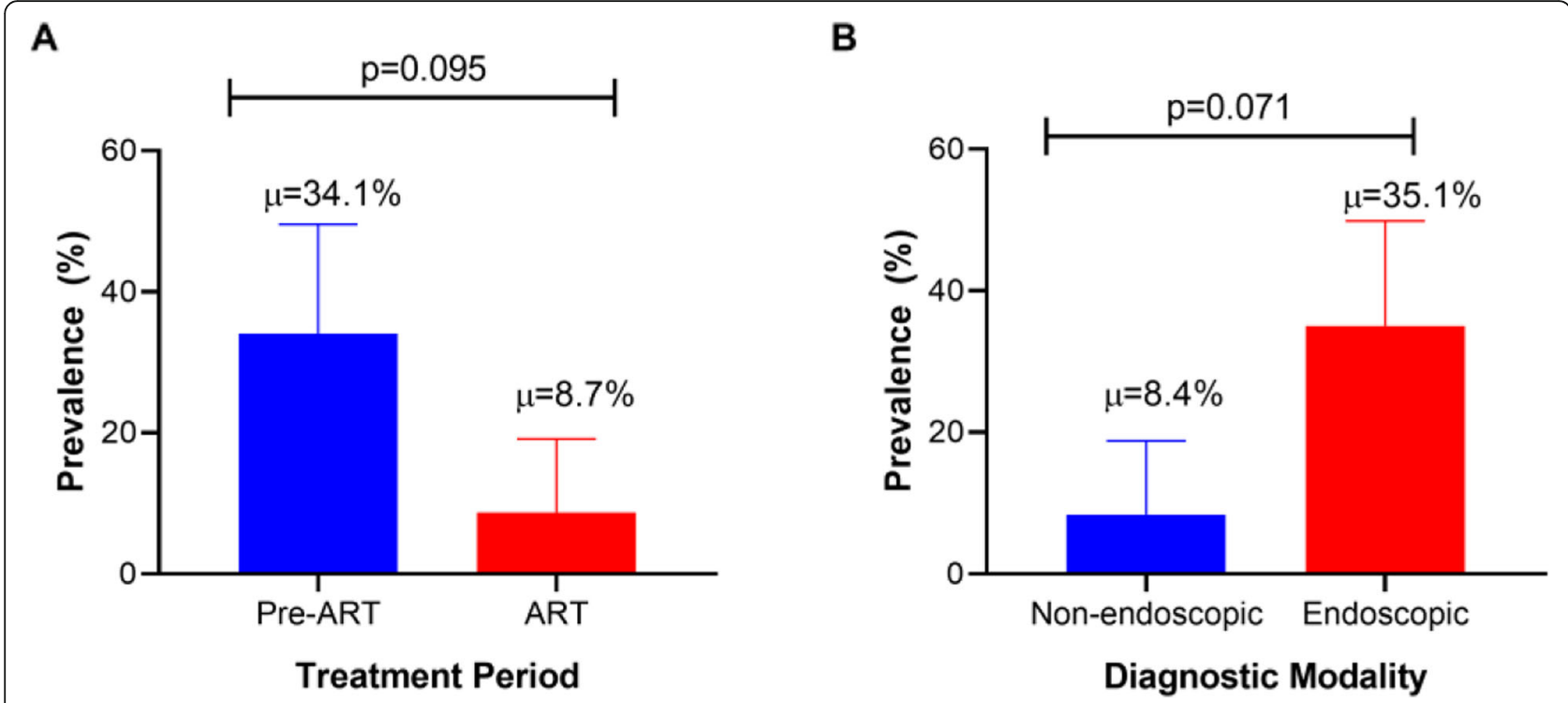

Fig. 6 Mean prevalence of HIV-associated esophageal candidiasis by antiretroviral therapy era (a) and diagnostic modality (b)

Kaposi's sarcoma, which are common and may co-occur with OC [37].

\section{Limitations of the study}

This study has some important limitations. Firstly, in over 10,000 cases of OC, the method of diagnosis was not specified or the disease was diagnosed clinically. This increases the risk of overestimation of the true burden of the disease; especially that HSV esophagitis and other viral esophagitis are equally common in the African population. Secondly, microbiological confirmation and speciation of the etiologic confirmation were not reported in all studies. These are very important areas for future studies. Thirdly, there was a very high degree of statistical heterogeneity in this study. This is due to the vast difference in the diagnostic methods, the population studied (denominator), and study design. However, we minimize this by performing sensitivity analysis and constructing a cumulative prevalence analysis in addition to the traditional pooled meta-analysis.

\section{Conclusion}

Overall, our pooled data from this systematic review suggest a trend towards a declining prevalence of $\mathrm{OC}$ among PLHIV in the ART era in SSA. However, OC remains a common problem among PLHIV. Treatment outcomes and etiology of the disease largely remain unknown. This has a clinical implication in the choice of empirical antifungal therapy for suspected cases. Continuous active surveillance through OGD, empirical studies into microbiology and optimal antifungal treatment, and the impact of OC on quality of life of PLHIV in SSA are subjects for future studies.

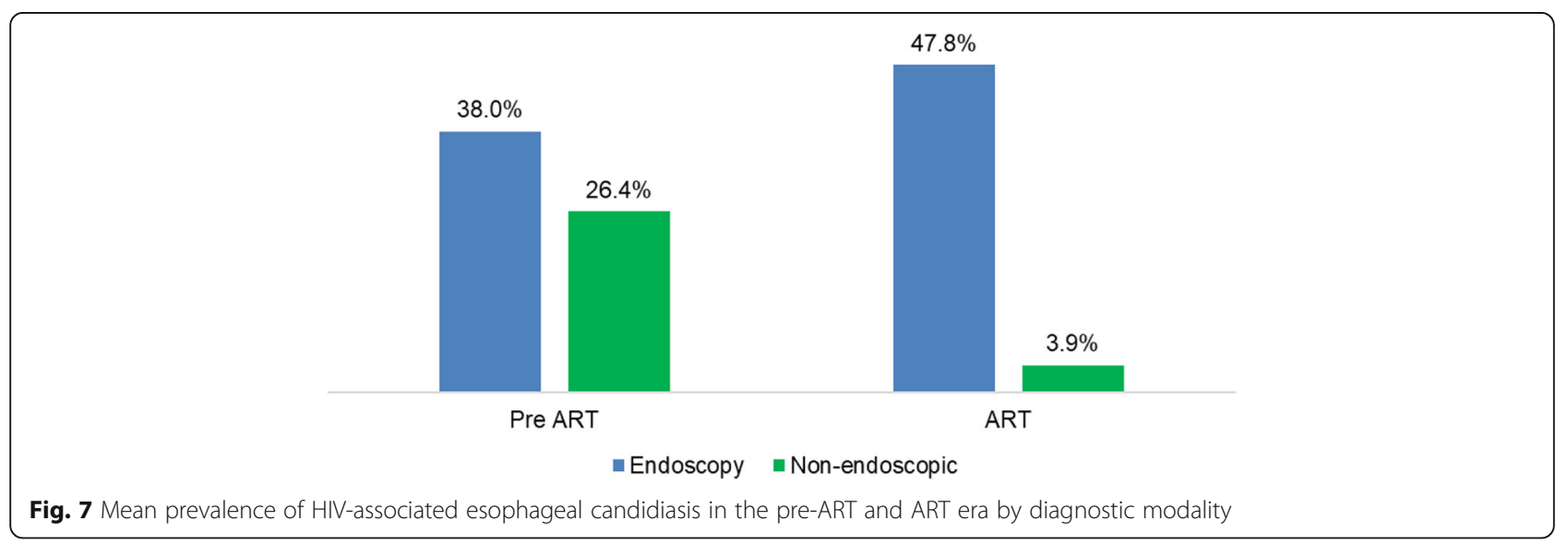




\section{Abbreviations}

OC: Esophageal candidiasis; SSA: Sub-Saharan Africa; ART: Antiretroviral therapy; HIV/AIDs: Human immune deficiency virus/acquired immune deficiency syndrome; PLHIV: Persons living with HIV;

OGD: Esophagoduodenoscopy

\section{Acknowledgements}

None

\section{Authors' contributions}

Conceptualisation: Felix Bongomin. Data curating: Ronald Olum and Felix Bongomin. Data analysis: Ronald Olum. Writing-original draft: Felix Bongomin and Ronald Olum. Writing and review of the final manuscript: Ronal Olum, Joseph Baruch Baluku, Ronald Okidi, Irene Andia-Biraro, and Felix Bongomin. Final manuscript: The authors read and approved the final manuscript.

\section{Authors' information}

Ronal Olum is a fourth year Bachelor of Medicine and Bachelor of Surgery student at School of Medicine, Makerere University. Joseph Baruch Baluku is an Internal Medicine Physician at Mulago National Referral Hospital and Mildmay Uganda. Ronald Okidi is a general surgeon at St Mary's Hospital Lacor. Irene Andia-Biraro is an Internal Medicine Physician and a Senior Lecturer in the Department of Medicine, Makerere University. Felix Bongomin is a Lecturer in Immunology and Medical Microbiology at the Department of Microbiology in Gulu University and a Senior House Officer in Internal Medicine in the Department of Medicine, Makerere University.

\section{Funding}

No funding was received for this work.

\section{Availability of data and materials}

The datasets analyzed during the current study are available from the corresponding author on reasonable request.

\section{Ethics approval and consent to participate}

This study analyzed published studies without identifiable data of patients, as such ethical approvals were not required.

\section{Consent for publication}

Not applicable

\section{Competing interests}

The authors declare no conflict of interest in this work.

\section{Author details}

${ }^{1}$ School of Medicine, College of Health Sciences, Makerere University, Kampala, Uganda. ${ }^{2}$ Directorate of Programs, Mildmay Uganda, Wakiso Uganda. ${ }^{3}$ Division of Pulmonology, Mulago National Referral Hospital, Kampala, Uganda. ${ }^{4}$ Department of General Surgery, St. Mary's Hospital Lacor, Gulu, Uganda. ${ }^{5}$ Department of Medicine, School of Medicine, College of Health Sciences, Makerere University, Kampala, Uganda. ${ }^{6}$ Medical Research Council/Uganda Virus Research Institute and London School of Hygiene and Tropical Medicine Uganda Research Unit, Entebbe, Uganda. ${ }^{7}$ Department of Medical Microbiology and Immunology, Faculty of Medicine, Gulu University, Gulu, Uganda.

\section{Received: 20 July 2020 Accepted: 14 September 2020}

Published online: 23 September 2020

\section{References}

1. UNAIDS. 2020 Global AIDS Update — seizing the moment - tackling entrenched inequalities to end epidemics. Geneva 2020. https://www. unaids.org/en/resources/documents/2020/global-aids-report.

2. Joint United Nations Programme on HIV/AIDS. UNAIDS Data 2019. Geneva 2019. https://www.unaids.org/en/resources/documents/2019/2019-UNAIDSdata.

3. Chopra S, Arora U. Skin and mucocutaneous manifestations: useful clinical predictors of HIV/AIDS. J Clin Diagn Res. 2012;6(10):1695-8. Epub 2013/02/ 02. PubMed PMID: 23373031; PubMed Central PMCID. PMCPMC3552207. https://doi.org/10.7860/JCDR/2012/4615.2633.
4. Oninla OA. Mucocutaneous manifestations of HIV and the correlation with WHO clinical staging in a tertiary hospital in Nigeria. AIDS Res Treat. 2014; 2014:360970. Epub 2015/01/15. PubMed PMID: 25587439; PubMed Central PMCID: PMCPMC4283442. https://doi.org/10.1155/2014/360970.

5. World Health Organization. WHO case definitions of HIV for surveillance and revised clinical staging and immunological classification of HIV-related disease in adults and children: World Health Organization; 2007.

6. Vazquez JA. Optimal management of oropharyngeal and esophageal candidiasis in patients living with HIV infection. HIV AIDS (Auckl). 2010;2:89101. https://doi.org/10.2147/hiv.s6660 Epub 2010/01/01. PubMed PMID: 22096388; PubMed Central PMCID: PMCPMC3218701.

7. Nishimura S, Nagata N, Shimbo T, Asayama N, Akiyama J, Ohmagari N, et al. Factors associated with esophageal candidiasis and its endoscopic severity in the era of antiretroviral therapy. PLoS One. 2013;8(3):e58217.

8. Kliemann DA, Pasqualotto AC, Falavigna M, Giaretta T, Severo LC. Candida esophagitis: species distribution and risk factors for infection. Rev Inst Med Trop Sao Paulo. 2008:50(5):261-3. https://doi.org/10.1590/s003646652008000500002 Epub 2008/10/25. PubMed PMID: 18949340.

9. Mohamed AA, Lu XL, Mounmin FA. Diagnosis and treatment of esophageal candidiasis: current updates. Can J Gastroenterol Hepatol. 2019;2019: 3585136. Epub 2019/11/28. PubMed PMID: 31772927; PubMed Central PMCI D: PMCPMC6854261. https://doi.org/10.1155/2019/3585136.

10. Mohamed FA, Lule GN, Nyong'o A, Bwayo J, Rana FS. Prevalence of Helicobacter pylori and endoscopic findings in HIV seropositive patients with upper gastrointestinal tract symptoms at Kenyatta National Hospital, Nairobi. East Afr Med J. 2002;79(5):226-31.

11. Smith E, Orholm M. Trends and patterns of opportunistic diseases in Danish AIDS patients 1980-1990. Scand J Infect Dis. 1990;22(6):665-72

12. Sewankambo N, Mugerwa RD, Goodgame R, Carswell JW, Moody A, Lloyd G, et al. Enteropathic AIDS in Uganda. An endoscopic, histological and microbiological study. AIDS. 1987;1(1):9-13 Epub 1987/05/01. PubMed PMID 3122796.

13. Robertson KD, Nagra N, Mehta D. Esophageal Candidiasis. StatPearls. Treasure Island: StatPearls Publishing; 2020.

14. Moher D, Liberati A, Tetzlaff J, Altman DG, Group P. Preferred reporting items for systematic reviews and meta-analyses: the PRISMA statement. PLoS Med. 2009;6(7):e1000097. Epub 2009/07/22. PubMed PMID: 19621072; PubMed Central PMCID: PMCPMC2707599. https://doi.org/10.1371/journal. pmed.1000097.

15. World Health Organization. Scaling up antiretroviral therapy in resourcelimited settings: treatment guidelines for a public health approach. Geneva: World Health Organization; 2004. p. 9241591552.

16. World Health Organization. Progress report 2016: prevent HIV, test and treat all: WHO support for country impact. Geneva: WHO; 2016.

17. Lawson-Ananissoh LM, Bouglouga O, Bagny A, El-Hadji RY, Sewu KE, Kaaga $L$, et al. Factors associated with the death of patients infected with the human immunodeficiency virus hospitalized in the gastroenterology department of the Campus Teaching Hospital of Lomé, Togo. Med Sante Tropicales. 2018;28(3):302-6.

18. Rubaihayo J, Tumwesigye NM, Konde-Lule J, Wamani H, Nakku-Joloba E, Makumbi F. Frequency and distribution patterns of opportunistic infections associated with HIV/AIDS in Uganda. BMC Res Notes. 2016;9(1):501. Epub 2016/12/09. PubMed PMID: 27927247; PubMed Central PMCID: PMCP MC5142427. https://doi.org/10.1186/s13104-016-2317-7.

19. Bagny A, Bouglouga O, Lawson-Ananisoh LM, Kaaga YL, Kotosso A, Yacoubou Rel H, et al. Panorama of digestives violations related to HIV in CHU Campus in Lome (Togo). Med Sante Trop. 2015;25(3):312-5. Epub 2015/06/04.PubMed PMID: 26039374. https://doi.org/10.1684/mst.2015.0472.

20. Brentlinger PE, Silva WP, Vermund SH, Valverde $E$, Buene M, Moon TD. Practical management of HIV-associated anemia in resource-limited settings: prospective observational evaluation of a new Mozambican guideline. AIDS Res Hum Retrovir. 2016:32(1):12-25. Epub 2015/07/17. PubMed PMID: 26178574; PubMed Central PMCID: PMCPMC4692124. https://doi.org/10. 1089/AID.2015.0030

21. Preidis GA, McCollum ED, Mwansambo C, Kazembe PN, Schutze GE, Kline MW. Pneumonia and malnutrition are highly predictive of mortality among African children hospitalized with human immunodeficiency virus infection or exposure in the era of antiretroviral therapy. J Pediatr. 2011;159(3):484-9.

22. Zachariah R, Harries K, Moses M, Manzi M, Line A, Mwagomba B, et al. Very early mortality in patients starting antiretroviral treatment at primary health centres in rural Malawi. Tropical Med Int Health. 2009;14(7):713-21. 
23. Ravera M, Reggiori A, Agliata AM, Rocco RP. Evaluating diagnosis and treatment of oral and esophageal candidiasis in Ugandan AIDS patients. Emerg Infect Dis. 1999;5(2):274-7. Epub 1999/04/30. PubMed PMID: 10221882; PubMed Central PMCID: PMCPMC2640695. https://doi.org/10. 3201/eid0502.990214.

24. Morgan D, Malamba SS, Orem J, Mayanja B, Okongo M, Whitworth JA. Survival by AIDS defining condition in rural Uganda. Sex Transm Infect. 2000;76(3):193-7. Epub 2000/08/29. PubMed PMID: 10961197; PubMed Central PMCID: PMCPMC1744150. https://doi.org/10.1136/sti.76.3.193..

25. Mushi MF, Ngeta N, Mirambo MM, Mshana SE. Predictors of esophageal candidiasis among patients attending endoscopy unit in a tertiary hospital, Tanzania: a retrospective cross-sectional study. Afr Health Sci. 2018;18(1):66-71.

26. Okeke EN, Agaba El, Achinge Gl, Malu AO. Upper gastrointestinal endoscopic findings in patients with HIV/AIDS at the Jos University Teaching Hospital, Nigeria. Niger J Med. 2003:12(4):202-5.

27. Andoulo FA, Kowo M, Ngatcha G, Ndam AN, Awouoyiegnigni B, Sida MB, et al. Prevalence of Helicobacter pylori prevalence and upper gastrointestinal endoscopy in HIV/AIDS patients with gastrointestinal symptoms in the University Teaching Hospitals in Cameroon. Med Sante Trop. 2016;26(3):278-82. Epub 2016/10/04. PubMed PMID: 27694084. https:// doi.org/10.1684/mst.2016.0582.

28. Kelly P, Summerbell C, Ngwenya B, Mandanda B, Hosp M, Fuchs D, et al. Systemic immune activation as a potential determinant of wasting in Zambians with HIV-related diarrhoea. QJM. 1996;89(11):831-8.

29. Swindells S, Evans S, Zackin R, Goldman M, Haubrich R, Filler SG, et al. Predictive value of HIV-1 viral load on risk for opportunistic infection. J Acq Imm Def Syndr (1999). 2002;30(2):154-8. Epub 2002/06/05. PubMed PMID: 12045677. https://doi.org/10.1097/00042560-200206010-00003.

30. Weissberg D, Mubiru F, Kambugu A, Fehr J, Kiragga A, von Braun A, et al. Ten years of antiretroviral therapy: incidences, patterns and risk factors of opportunistic infections in an urban Ugandan cohort. PLoS One. 2018; 13(11):e0206796. Epub 2018/11/02. PubMed PMID: 30383836; PubMed Central PMCID: PMCPMC6211746. https://doi.org/10.1371/journal.pone. 0206796.

31. Kaplan JE, Hanson DL, Jones JL, Dworkin MS, the A, Adolescent spectrum of HIVDPI. Viral load as an independent risk factor for opportunistic infections in HIV-infected adults and adolescents. AIDS. 2001;15(14).

32. Chimukangara B, Lessells RJ, Rhee S-Y, Giandhari J, Kharsany ABM, Naidoo K, et al. Trends in pretreatment HIV-1 drug resistance in antiretroviral therapynaive adults in South Africa, 2000-2016: a pooled sequence analysis. E Clin Med. 2019;9:26-34.

33. Tymejczyk O, Brazier E, Yiannoutsos CT, Vinikoor M, van Lettow M, Nalugoda $F$, et al. Changes in rapid HIV treatment initiation after national "treat all" policy adoption in 6 sub-Saharan African countries: regression discontinuity analysis. PLoS Med. 2019;16(6):e1002822.

34. Osler M, Hilderbrand K, Goemaere E, Ford N, Smith M, Meintjes G, et al. The continuing burden of advanced HIV disease over 10 years of increasing antiretroviral therapy coverage in South Africa. Clin Infect Dis. 2018; 66(suppl_2):S118-S25. Epub 2018/03/08. PubMed PMID: 29514233; PubMed Central PMCID: PMCPMC5850025. https://doi.org/10.1093/cid/cix1140.

35. Calmy A, Ford N, Meintjes G. The persistent challenge of advanced HIV disease and AIDS in the era of antiretroviral therapy. Clin Infect Dis. 2018; 66(suppl_2):S103-SS5. Epub 2018/03/08. PubMed PMID: 29514231; PubMed Central PMCID: PMCPMC5850411. https://doi.org/10.1093/cid/cix1138.

36. Pappas PG, Kauffman CA, Andes DR, Clancy CJ, Marr KA, Ostrosky-Zeichner L, et al. Clinical practice guideline for the management of candidiasis: 2016 update by the Infectious Diseases Society of America. Clin Infect Dis. 2016; 62(4):e1-e50.

37. Bhaijee F, Subramony C, Tang SJ, Pepper DJ. Human immunodeficiency virus-associated gastrointestinal disease: common endoscopic biopsy diagnoses. Pathol Res Int. 2011:2011:247923. Epub 2011/05/12. PubMed PMID: 21559197; PubMed Central PMCID: PMCPMC3090068. https://doi.org/ 10.4061/2011/247923.

\section{Publisher's Note}

Springer Nature remains neutral with regard to jurisdictional claims in published maps and institutional affiliations.

\section{Ready to submit your research? Choose BMC and benefit from}

- fast, convenient online submission

- thorough peer review by experienced researchers in your field

- rapid publication on acceptance

- support for research data, including large and complex data types

- gold Open Access which fosters wider collaboration and increased citations

- maximum visibility for your research: over $100 \mathrm{M}$ website views per year

At BMC, research is always in progress.

Learn more biomedcentral.com/submissions 